Original Research Article

\title{
Clinical Features and Therapeutic Outcomes of Post-colectomy Enteritis with Ulcerative Colitis
}

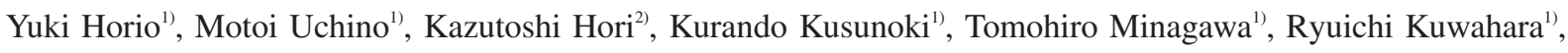 \\ Kozo Kataoka ${ }^{1)}$, Naohito Beppu ${ }^{1)}$, Masataka Ikeda ${ }^{1)}$ and Hiroki Ikeuchi ${ }^{1)}$ \\ 1) Department of Gastroenterological Surgery, Hyogo College of Medicine, Hyogo, Japan \\ 2) Department of Intestinal Inflammation Research, Hyogo College of Medicine, Hyogo, Japan
}

\begin{abstract}
Objectives: Few reports are available on post-colectomy enteritis (PCE) with ulcerative colitis (UC), which can be severe and sometimes fatal. The clinical characteristics are unclear, and treatment and diagnosis protocols have not been established. We aimed to investigate the incidence, clinical characteristics, diagnostic criteria, and therapeutic outcomes of PCE in this study.

Methods: Patients with UC who underwent colectomy between April 2010 and December 2019 were included in this study. We retrospectively analyzed patients who developed PCE and excluded patients with other forms of enteritis.

Results: We performed 829 colectomies because of a preoperative diagnosis of UC. Eleven and four patients were diagnosed with Crohn's disease and indeterminate colitis after surgery, respectively; 22 patients developed enteritis in the perioperative period. We excluded six patients with backwash ileitis, five with prepouch ileitis, three with infectious enteritis, and one with ischemic enteritis. In total, 7/814 (0.8\%) patients developed PCE. All patients with PCE had pancolitis. PCE was observed a median of 33 (12-248) days after surgery. Endoscopy showed friable and granular mucosa. The extent of disease included various types such as pan-enteritis with diffuse type, pan-enteritis and mild inflammation in the middle ileum, and only ileitis. Gastroduodenitis-associated UC developed in 6/7 cases. All patients improved with tumor necrosis factor alpha (TNF $\alpha$ ) antagonists even if TNF $\alpha$ antagonists had not been effective for colitis.

Conclusions: PCE was rare. The mucosal endoscopic findings were similar to those of UC, and the extent of disease varied. TNF $\alpha$ antagonist administration for PCE was effective.
\end{abstract}

\section{Keywords}

ulcerative colitis, post-colectomy enteritis, small bowel lesion, tumor necrosis factor alpha antagonists

J Anus Rectum Colon 2021; 5(4): 405-413

\section{Introduction}

Ulcerative colitis (UC) is generally superficial, and diffuse inflammation is limited to the colon and rectum. However, UC can occasionally affect the small intestine, such as backwash ileitis. The incidence of backwash ileitis has been reported to be approximately $10 \%-20 \%$ of all UC speci- mens[1-3]. The etiology has been attributed to stool regurgitation due to destruction of the ileocecal valve, resulting in villous, superficial inflammation and sometimes stenosis in the distal ileum. Whether backwash ileitis is associated with colorectal carcinoma or pouchitis is controversial[2-6]. Pouchitis is another possibility. Nonspecific inflammation of the ileal pouch mucosa occurs after total proctocolectomy 
and ileal pouch-anal anastomosis (IPAA) and has been reported to occur in $50 \%$ of surgical patients[7]. The third possibility is prepouch ileitis after pouch surgery. Prepouch ileitis is observed above the pouch $(1-50 \mathrm{~cm})$, and the inflammation gradually becomes mild. The clinical symptoms are increased stool frequency, bowel obstruction, and melena[8]. Most patients developed pouchitis and refractory disease[8,9].

The fourth possibility is diffuse enteritis/pan-enteritis, which causes inflammation in the small intestine, resembling UC-like lesions rather than Crohn's disease (CD) features[10,11]. These conditions occur during colostomy after colectomy and have been reported as post-colectomy enteritis (PCE) or pre-stomal terminal ileitis[12,13], which could be severe, has a high morbidity rate, and is sometimes fatal[14]. These lesions can be found from the ileum to the jejunum and may cause perforations, leading to peritonitis. Few reports are available on PCE, and the etiology is still unknown. We aimed to investigate the incidence, clinical characteristics, diagnosis, and therapeutic outcomes of PCE in this study.

\section{Methods}

\section{Patient selection and data collection}

Patients with UC who underwent colectomy at the Hyogo College of Medicine between April 2010 and December 2019 were included in this study. We retrospectively analyzed patients who developed PCE among these patients. The diagnosis of UC was based on clinical, endoscopic, radiological, and intraoperative findings and pathological evaluation of biopsied and resected specimens.

The data collected included the following: sex; age at surgery; duration of disease; disease severity; extent of disease; primary sclerosing cholangitis (PSC); preoperative pharmacotherapies such as corticosteroids, immunosuppressants (thiopurines, including azathioprine and 6-mercaptopurine), calcineurin inhibitors such as tacrolimus (TAC) and cyclosporine A and biological therapy such as infliximab (IFX), adalimumab (ADA), and golimumab (GLM); and concomitant postoperative complications. UC disease activity was primarily assessed according to clinical features using the criteria from Truelove and Witts[15]. The total dose of administered corticosteroids was converted into the prednisolone (PSL) dose and calculated based on the corticosteroid dose administered since the initial onset of UC. The immunomodulators, calcineurin inhibitors, and biologics administered were determined based on medication history, irrespective of the dosing period.

\section{Diagnostic criteria for post-colectomy enteritis}

PCE was suspected based on clinical symptoms, such as intractable diarrhea $(\geq 1,500 \mathrm{ml}$ for two consecutive days with an antidiarrheal), anemia progression due to intestinal bleeding that required blood transfusion, endoscopic hemostasis, radiological intervention and/or surgery, intractable and persistent abdominal pain without surgical site infection, and small-intestinal perforation due to intestinal inflammation and/or ulceration during the postoperative course.

The diagnostic procedure for PCE was as follows: 1) Evaluate the presence of a friable mucosa, granular mucosa, or multiple aphthae/erosions/ulcers by gastrointestinal endoscopy of the ostomy site and operative specimens of the small intestine. Friable mucosa, granular mucosa, and multiple aphthae were used as diagnostic criteria for gastroduodenitis-associated UC (GDUC) by Hori et al.[16]. The extent of disease was confirmed by capsule endoscopy or laparotomy findings. It was important to confirm GDUC and a bamboo joint-like appearance of the gastric body and cardia by upper endoscopy to exclude CD[17].

2) Perform a stool culture to rule out infectious enteritis. Regarding Clostridium difficile ( $C$. difficile) enteritis, we conducted a nucleic acid amplification test for the $C$. difficile toxin $\mathrm{B}$ gene. The presence of cytomegalovirus (CMV) colitis was defined by the presence of intranuclear or intracellular inclusion bodies and/or a positive immunohistochemistry assay on histology.

3) Check for the use of a nonsteroidal anti-inflammatory drug (NSAID) to exclude NSAID ulcers.

4) Identify evidence of inflammation caused by UC to exclude other enteritis conditions based on the diagnostic criteria and histological findings of the biopsy taken during endoscopic examination or an operative specimen. We provided details of the exclusion criteria, such as $\mathrm{CD}$, Behçet's disease (BD), infectious enteritis, celiac disease, autoimmune enteritis, amyloidosis, eosinophilic gastroenteritis, ischemic enteritis, and IgA vasculitis (Henoch-Schönlein purpura), below.

\section{Exclusion criteria}

First, we excluded CD and indeterminate colitis (IC). CD was diagnosed according to the criteria established by the RGIBD[18] and the histological features of colectomy specimens. CD-like features were granulomas, transmural lymphoid aggregates, and fissures. IC was defined according to the Montreal classification in patients for whom colectomy had been performed and the pathologists were unable to make a definitive diagnosis of either CD or UC after a full examination of the postoperative colectomy specimens[19].

Regarding other enteritides, we excluded NSAID ulcers, $\mathrm{CD}, \mathrm{BD}$, infectious enteritis, celiac disease, autoimmune enteritis, amyloidosis, eosinophilic gastroenteritis, ischemic enteritis, and IgA vasculitis. NSAID users were defined as patients who had taken such medication every day for 7 days. The amount used was also described in detail for each pa- 


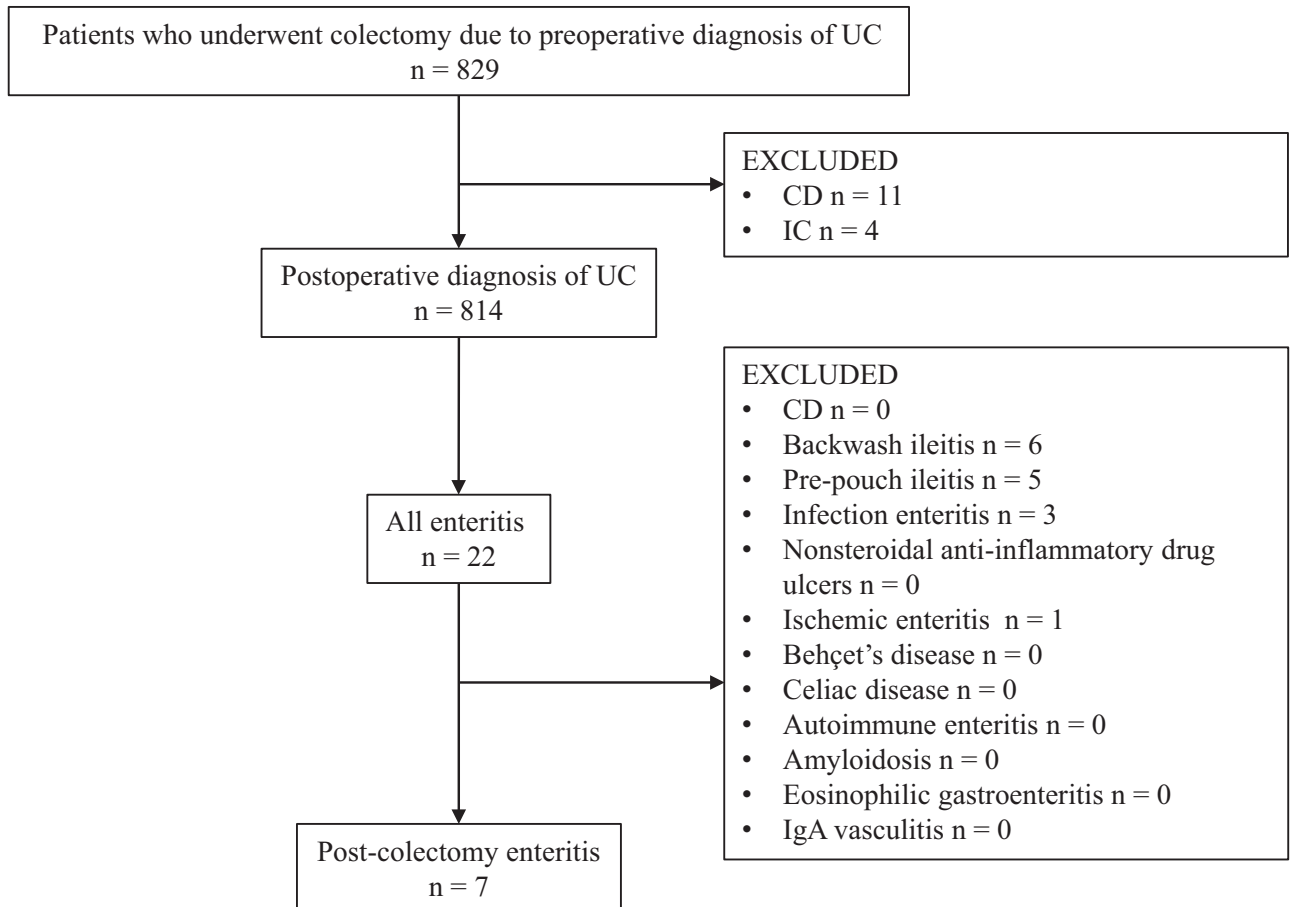

Figure 1. Flow diagram for enrolling patients with PCE.

tient. BD was diagnosed based on the International Study Group for BD criteria[20]. The diagnosis of eosinophilic gastroenteritis was made according to the criteria of Talley et al.[21]. The diagnosis of $\operatorname{IgA}$ vasculitis was made using the European League Against Rheumatism/Paediatric Rheumatology International Trials Organisation/Paediatric Rheumatology European Society (EULAR/PRINTO/PRES) criteria[22]. Celiac disease, autoimmune enteritis, amyloidosis, and ischemic enteritis were excluded by histological findings of celiac disease-like features such as villous atrophy; crypt hyperplasia and increased intraepithelial lymphocytes[23]; autoimmune enteritis-like features such as partial/complete villous blunting, crypt apoptotic bodies, and intraepithelial lymphocytes[24]; amyloidosis-like features such as amyloid protein deposits; and ischemic enteritis-like features such as thrombosis and fibrinoid necrosis.

We also excluded patients with backwash ileitis and prepouch ileitis. Backwash ileitis was defined as the presence of macroscopic or histological inflammation in the small intestine and cecal involvement at initial surgery. Prepouch ileitis was defined as any endoscopically noted inflammation in the ileum that was continuous for at least $2 \mathrm{~cm}$ proximal to the pouch inlet based on the pathological presence of inflammation or inflammatory cells after pouch surgery[9]. Diversion enteritis/pouchitis was defined as inflammation of the prepouch and pouch up to the stoma closure. Pouchitis was defined by typical clinical symptoms, such as an increased number of bowel movements, melena, aggravation of incontinence, and at least one abnormal pouch endoscopy during the manifestation of one of these symptoms after pouch surgery.

\section{Statistical analysis}

Statistical analysis was performed as follows. Categorical variables were compared using Fisher's exact test. Numerical variables are expressed as medians and ranges, and they were compared using the Mann-Whitney $U$ test. The level of statistical significance was set at $p<0.05$. Each individual factor with a significant $p$-value in univariate analysis was subsequently entered into a stepwise logistic regression model. JMP ver. 14 (SAS Institute, Inc., Cary, NC, USA) was used to perform all analyses.

\section{Results}

We performed 829 colectomies due to a preoperative diagnosis of UC. Eleven patients were diagnosed with $\mathrm{CD}$, and four patients were diagnosed with IC after surgery. We reviewed 814 UC patients in total. Twenty-two patients developed enteritis in the perioperative period. Six patients developed backwash ileitis; five patients developed prepouch ileitis; three patients developed infectious enteritis (Escherichia coli of serotype O-143, vancomycin-resistant enterococci, and methicillin-resistant Staphylococcus aureus); and one patient developed ischemic enteritis. No patients had BD, NSAID ulcers, celiac disease, autoimmune enteritis, amyloidosis, eosinophilic gastroenteritis, or IgA vasculitis. A total of $7 / 814(0.8 \%)$ patients developed PCE (Figure $1)$.

The characteristics of the patients with PCE are presented 
Table 1. Patient Characteristics of Post-colectomy Enteritis.

\begin{tabular}{|c|c|c|c|c|c|c|c|c|c|c|}
\hline \multirow[b]{2}{*}{ Case } & \multirow{2}{*}{$\begin{array}{c}\text { Age } \\
\text { range at } \\
\text { surgery }\end{array}$} & \multirow{2}{*}{$\begin{array}{c}\text { Duration } \\
\text { of disease } \\
\text { (month) }\end{array}$} & \multirow{2}{*}{$\begin{array}{l}\text { Disease } \\
\text { severity }\end{array}$} & \multirow{2}{*}{$\begin{array}{l}\text { Extent of } \\
\text { disease }\end{array}$} & \multicolumn{3}{|c|}{ Treatment before surgery } & \multirow{2}{*}{$\begin{array}{c}\text { Indication of } \\
\text { surgery }\end{array}$} & \multirow{2}{*}{$\begin{array}{c}\text { Emergency } \\
\text { surgery }\end{array}$} & \multirow[b]{2}{*}{ Procedure } \\
\hline & & & & & $\begin{array}{l}\text { Total PSL } \\
\text { dose }(\mathrm{mg})\end{array}$ & $\mathrm{IM} / \mathrm{CI}$ & $\mathrm{BIO}$ & & & \\
\hline 1 & $20 \mathrm{~s}$ & 75.8 & severe & pancolitis & 10,000 & $\begin{array}{l}\text { TAC, } \\
\text { AZA }\end{array}$ & - & refractory & + & $\begin{array}{l}\text { IPAA with } \\
\text { ileostomy }\end{array}$ \\
\hline 2 & $60 \mathrm{~s}$ & 132.1 & mild & pancolitis & 2,000 & - & - & cancer & - & $\begin{array}{l}\text { IPAA with } \\
\text { ileostomy }\end{array}$ \\
\hline 3 & $40 \mathrm{~s}$ & 302.1 & mild & pancolitis & 14,500 & - & - & cancer & - & $\begin{array}{l}\text { IPAA with } \\
\text { ileostomy }\end{array}$ \\
\hline 4 & $50 \mathrm{~s}$ & 124.2 & severe & pancolitis & 2,175 & TAC & IFX & refractory & - & $\begin{array}{l}\text { IPAA with } \\
\text { ileostomy }\end{array}$ \\
\hline 5 & $20 \mathrm{~s}$ & 8.6 & severe & pancolitis & 1,000 & $\begin{array}{l}\text { TAC, } \\
\text { AZA }\end{array}$ & $\begin{array}{l}\text { IFX, } \\
\text { ADA }\end{array}$ & refractory & + & $\begin{array}{l}\text { IPAA with } \\
\text { ileostomy }\end{array}$ \\
\hline 6 & $50 \mathrm{~s}$ & 44.6 & severe & pancolitis & 500 & $\begin{array}{l}\text { TAC, } \\
\text { AZA }\end{array}$ & GLM & refractory & - & $\begin{array}{l}\text { IPAA with } \\
\text { ileostomy }\end{array}$ \\
\hline 7 & $80 \mathrm{~s}$ & 38.8 & severe & pancolitis & 200 & - & - & $\begin{array}{l}\text { Toxic mega } \\
\text { colon }\end{array}$ & + & $\begin{array}{l}\text { Total colectomy } \\
\text { (Hartmann) }\end{array}$ \\
\hline
\end{tabular}

$\mathrm{PSL}=$ Prednisolone, $\mathrm{IM}=$ Immuno modulator, $\mathrm{CI}=$ Calcineurin inhibitor, $\mathrm{AZA}=$ Azathioprine, $\mathrm{TAC}=$ Tacrolimus, $\mathrm{BIO}=\mathrm{Biologics}, \mathrm{IFX}=\mathrm{Infliximab}$, $\mathrm{ADA}=$ Adalimumab, $\mathrm{GLM}=$ Golimumab, IPAA $=$ Ileal pouch-anal anastomosis

Table 2. A Comparison of the Post-colectomy Enteritis Group and the Non-post-colectomy Enteritis Group.

\begin{tabular}{lcccc}
\hline & $\begin{array}{c}\text { All patients } \\
\mathrm{n}=814\end{array}$ & $\begin{array}{c}\text { PCE } \\
\mathrm{n}=7\end{array}$ & $\begin{array}{c}\text { non-PCE } \\
\mathrm{n}=807\end{array}$ & $p$-value \\
\hline Gender (male/female) & $529 / 285$ & $2 / 5$ & $527 / 280$ & 0.054 \\
Age at initial surgery (years) & $46.9 \pm 17.9$ & $42.9 \pm 26.2$ & $46.9 \pm 17.8$ & 0.573 \\
Disease duration (months) & $68.5(0.2-590.4)$ & $75.8(8.6-302.1)$ & $68.4(0.3-590.4)$ & 0.974 \\
Pan-colitis & $697(85.6)$ & $7(100)$ & $690(85.5)$ & 0.602 \\
Severe disease & $269(33.1)$ & $5(71.4)$ & $264(32.7)$ & $0.043 *$ \\
Total given PSL dose (mg) & $3,025(0-20,000)$ & $2,175(200-14,500)$ & $3,055(0-20000)$ & 0.753 \\
Daily pre-operative PSL dose (mg/day) & $2.5(0-80)$ & $0(0-10)$ & $2.5(0-80)$ & 0.136 \\
Immunomodulator administration & $324(39.8)$ & $3(42.8)$ & $321(39.8)$ & 0.071 \\
Calcineurin inhibitors & $262(32.2)$ & $4(57.1)$ & $258(31.9)$ & 0.220 \\
Biologics administration & $315(38.7)$ & $3(42.9)$ & $312(38.7)$ & 1.000 \\
$\quad$ Infliximab & $270(33.2)$ & $2(28.6)$ & $268(33.3)$ & 1.000 \\
Adalimumab & $92(11.32)$ & $1(14.3)$ & $91(11.3)$ & 0.570 \\
Golimumab & $14(1.7)$ & $1(14.3)$ & $13(1.6)$ & 0.115 \\
\hline
\end{tabular}

$\mathrm{PCE}=$ post colectomy enteritis, $\mathrm{PSL}=$ prednisolone, Data are numbers with percentages in parentheses, unless otherwise indicated. Continuous variables are indicated as mean \pm standard deviation and median (range). $* p<0.05$ (significantly different)

in Table 1. The disease severity was mild in two patients and severe in four patients. No patients developed PSC. Regarding preoperative pharmacotherapy, the median total administered PSL dose was 2,000 (200-10,000) mg; immunomodulators were administered to three patients (cases 1,5 , and 6); calcineurin inhibitors were administered to four patients (case 1, 4, 5, and 6); and biologics were administered to three patients (cases 4, 5, and 6). All patients had pancolitis, and the surgical indications were refractory symptoms in five patients and cancer in two patients. Three patients with fulminant disease required emergency surgery. IPAA with ileostomy was performed in six patients, and total colectomy (Hartmann procedure) was performed in one pa- tient because of a toxic megacolon (case 7). The clinical characteristics of the PCE group and the non-PCE group are presented in Table 2. No significant differences in the sex, age at initial surgery, duration of disease, extent of disease, and pharmacotherapy, such as corticosteroids, immunosuppressants, calcineurin inhibitors, and biologic therapy, were noted between the PCE and non-PCE groups. The severe disease in five $(71.4 \%)$ patients with PCE resulted in a significantly higher rate of severe disease in the PCE group ( $p$ $=0.04)$.

The clinical findings of PCE are presented in Table 3. PCE developed after a median of 33 (12-248) postoperative days. PCE with colorectal cancer tended to have a later on- 
Table 3. Clinical Findings of Post-colectomy Enteritis.

\begin{tabular}{|c|c|c|c|c|c|c|c|c|c|c|c|c|}
\hline Case & POD & Symptoms & $\begin{array}{l}\text { Extent of } \\
\text { disease }\end{array}$ & GDUC & $\begin{array}{l}\text { CMV IgG } \\
\text { and IgM } \\
\text { serology }\end{array}$ & $\begin{array}{c}\text { CMV } \\
\text { histology }\end{array}$ & $\begin{array}{c}\text { CMV } \\
\text { antigenemia }\end{array}$ & $\begin{array}{l}\text { Stool } \\
\text { culture }\end{array}$ & C diffi & NSAID & $\begin{array}{l}\text { Treatment } \\
\text { of PCE }\end{array}$ & $\begin{array}{l}\text { Follow- } \\
\text { up terms } \\
\text { (months) }\end{array}$ \\
\hline 1 & 28 & perforation & $\begin{array}{l}\text { jejunum, } \\
\text { ileum }\end{array}$ & + & $\begin{array}{l}\text { IgG+ } \\
\text { IgM- }\end{array}$ & - & - & - & - & $\begin{array}{c}\text { Flurbiprofen } \\
\text { axetil } 50 \mathrm{mg} / 3 \\
\text { times }\end{array}$ & $\begin{array}{l}\mathrm{IFX}+ \\
\mathrm{GCV}\end{array}$ & 105.5 \\
\hline 2 & 90 & $\begin{array}{c}\text { hemorrhage } \\
\text { (massive } \\
\text { bleeding) }\end{array}$ & $\begin{array}{l}\text { jejunum, } \\
\text { ileum }\end{array}$ & + & $\begin{array}{l}\text { IgG+ } \\
\text { IgM- }\end{array}$ & + & + & - & - & - & $\begin{array}{l}\mathrm{IFX}+ \\
\mathrm{GCV}\end{array}$ & 90.1 \\
\hline 3 & 248 & hemorrhage & $\begin{array}{l}\text { ileum, } \\
\text { diverting } \\
\text { pre-pouch } \\
\text { and } \\
\text { pouch }\end{array}$ & + & $\begin{array}{l}\text { IgG+ } \\
\text { IgM- }\end{array}$ & - & - & - & - & - & IFX & 27.2 \\
\hline 4 & 15 & high output & $\begin{array}{l}\text { jejunum, } \\
\text { ileum }\end{array}$ & $\begin{array}{c}- \\
\text { (Atrophic } \\
\text { gastritis) }\end{array}$ & $\begin{array}{l}\text { IgG+ } \\
\text { IgM- }\end{array}$ & - & - & - & - & - & GLM & 12.1 \\
\hline 5 & 34 & high output & $\begin{array}{l}\text { jejunum, } \\
\text { ileum }\end{array}$ & + & $\begin{array}{l}\text { IgG+ } \\
\text { IgM- }\end{array}$ & - & - & - & - & - & IFX & 14.7 \\
\hline 6 & 33 & hemorrhage & $\begin{array}{c}\text { ileum, } \\
\text { diverting } \\
\text { pre-pouch } \\
\text { and } \\
\text { pouch }\end{array}$ & + & $\begin{array}{l}\text { IgG+ } \\
\text { IgM- }\end{array}$ & - & - & - & - & - & GLM & 4.1 \\
\hline 7 & 12 & hemorrhage & ileum & + & $\begin{array}{l}\text { IgG+ } \\
\text { IgM- }\end{array}$ & - & + & - & - & - & IFX & 3.9 \\
\hline
\end{tabular}

$\mathrm{POD}=$ Post operative date, GDUC $=$ Gastro-duodenitis with ulcerative colitis, $\mathrm{CMV}=$ Cytomegalovirus, $\mathrm{C}$ diffi $=$ Clostridium difficile, NSAID $=$ Nonsteroidal anti-inflammatory drug, IFX = Infliximab, GCV = Ganciclovir, GLM = Golimumab, PCE = Post-colectomy enteritis

set than PCE with a refractory disease. The clinical symptoms were an intractable high-output (HOP) syndrome in three patients, bleeding from the stoma in four patients, and perforation in one patient. All patients with hemorrhage required blood transfusions, and one patient required interventional radiology. The extent of PCE was pan-enteritis from the jejunum to the ileum in four patients. The details of the lesions were as follows: multiple punched-out ulcers and diffuse lesions from the jejunum to the ileal end (case 1); deep ulcer in the upper jejunum and the ileal end and mild disease in the middle ileum (case 2); multiple aphthous ulcers from the jejunum to the upper jejunum and severe inflammation in the ileal end (case 4); and multiple erosions in the middle of the jejunum and geographical ulcers, edema, mucus adhesions that were exacerbated as the depth of the ileum increased, and a circumferential ulcer in the ileal end (case 5). The other three patients had lesions limited to the ileum. There were no characteristic histological findings. Two patients had diverting ileitis/pouchitis at the same time (cases 3 and 6). A total of 6/7 patients were diagnosed with GDUC. One patient was diagnosed with atrophic gastritis (case 4). The representative endoscopic findings of PCE lesions are illustrated in Figure 2. Additionally, Figure 3 presents the histological findings of an ileal specimen resected from case 1 .

Regarding CMV and NSAID ulcers, one patient (case 2) had positive results from the mucosal viral assay of CMVDNA. Initially, the patient was treated with ganciclovir (GCV) for CMV enteritis. However, although the presence of CMV-DNA and CMV antigens disappeared, there was no improvement in the lesion, and the bleeding continued. Thus, the patient started corticosteroids for a diagnosis of PCE. For the patient with a punched ulcer (case 1), only the blood CMV-DNA test was positive, the mucosal viral assay of CMV-DNA was negative, and no pathological diagnosis was recognized. Thus, the patient was also diagnosed with PCE. The other patients had no evidence of CMV, and CMV enteritis was ruled out as there were no histological findings of CMV. One patient (case 1) received $50 \mathrm{mg}$ flurbiprofen axetil for postoperative pain. However, the medication was given as an intravenous drip, and the number of administrations was as low as three times. The patient was not a regular user of NSAIDs before surgery, and the lesions were punched ulcers from the jejunum to the ileum with perforation. For the above reason, the patient was not diagnosed with NSAID ulcers.

Regarding therapeutic outcomes, although three patients were initially administered PSL (cases 1, 2, and 3), they did not improve and switched to biologic therapy. The other patients were initially administered a biological therapy. In total, five patients were administered IFX, two patients were administered GLM, and all patients improved, even patients 

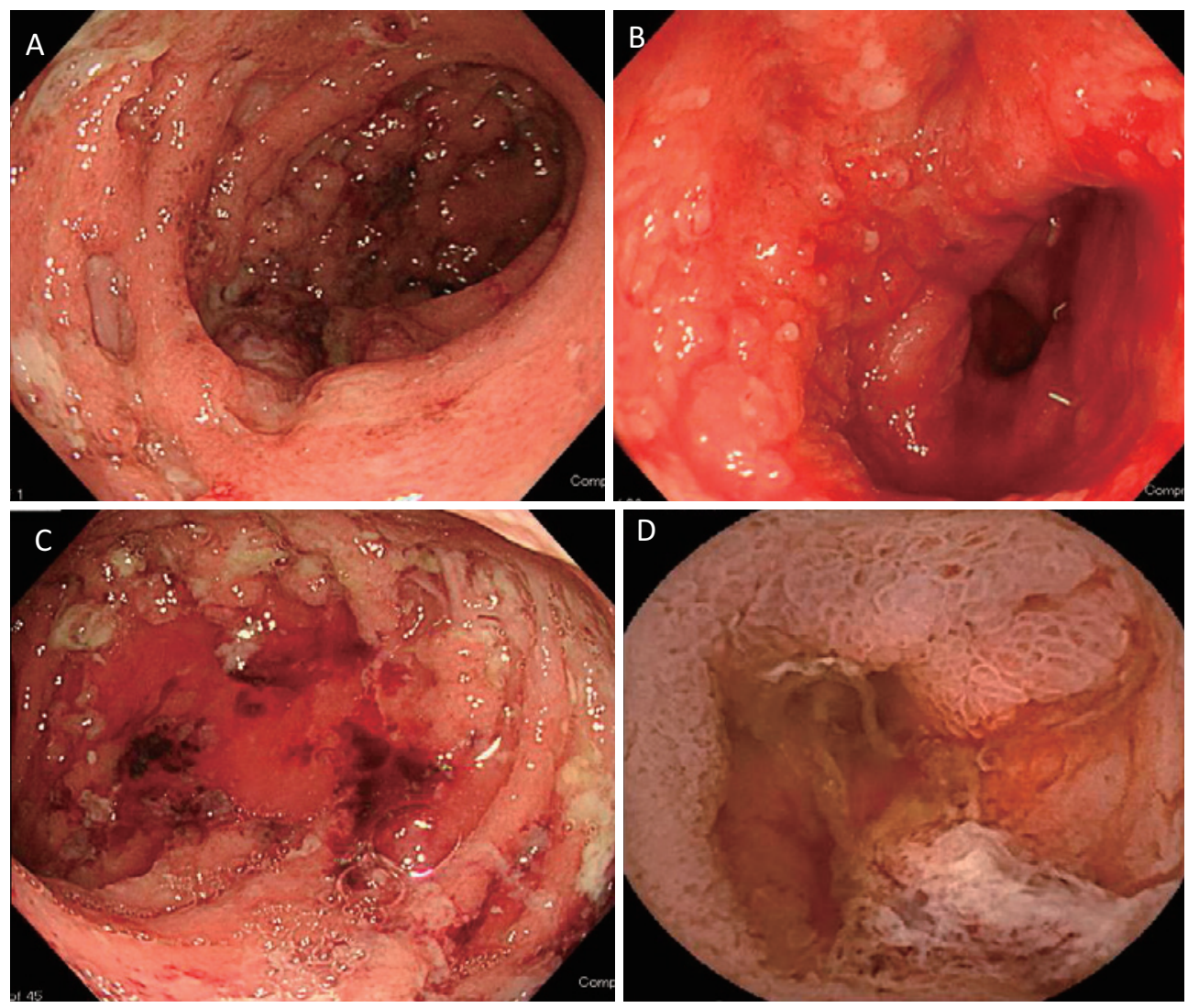

Figure 2. Representative findings of PCE. Friable and granular mucosa with A: punched-out ulcer, B: erosion and multiple aphthae, C: deep ulcer in the small intestine observed by endoscopy, and D: deep ulcer in the small intestine observed by capsule endoscopy.

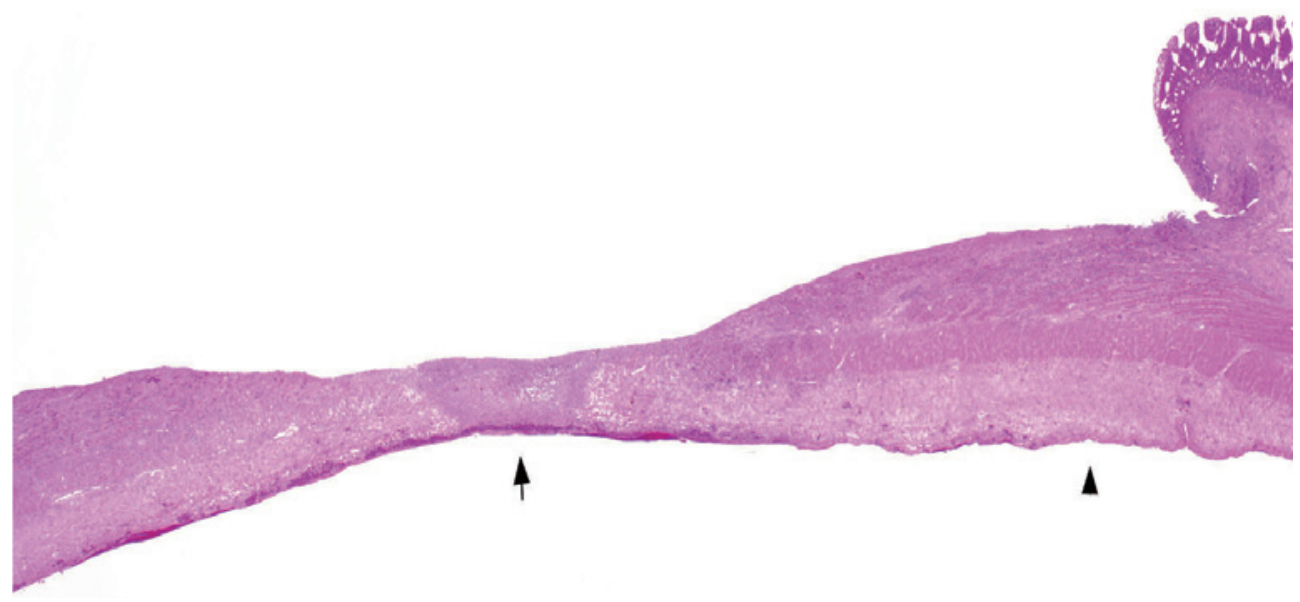

Figure 3. The resected specimen from ileum in case 1 showed a gently sloping, deep ulceration with abscess formation (arrow) in the subserosa, indicating perforation. Subserosal fibrosis (arrow head) and transmural lymhocytic infiltration were observed around the ulcer, suggesting chronic active inflammation.

(cases 4, 5, and 6) who were unresponsive to tumor necrosis factor alpha $(\mathrm{TNF} \alpha)$ antagonist treatment for colitis. The representative endoscopic findings of PCE lesions in remis- sion are illustrated in Figure 4. The median time to symptom improvement was 3.5 (2-10) days, and the median time to endoscopic remission was $4.9(0.6-13.1)$ months. In three 


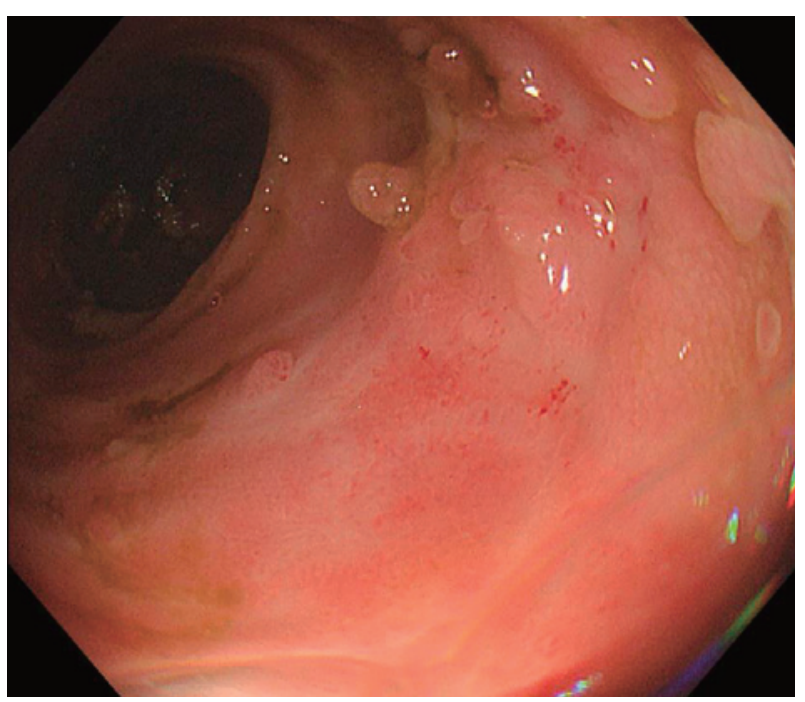

Figure 4. Representative findings of PCE in remission after the administration of $\mathrm{TNF} \alpha$ antagonists.

patients (cases 5, 6, and 7), biological treatment was continued, and for the other patients, the regimen was completed. No PCE recurrence developed during the observation period. However, one patient (case 3) experienced recurrence with diversion ileitis/pouchitis and recovered with topical corticosteroid treatments. The median observation period was 14.6 (3.9-105.5) months. Stoma closure was performed in four patients. Four patients did not develop pouchitis or pouch failure. Two patients (cases 2 and 7) did not undergo stoma closure due to their old age. The other patient (case 4) died because of the recurrence of cancer and peritoneal dissemination 27.2 months after the onset of enteritis.

\section{Discussion}

Herein, we report that the incidence of PCE was $0.8 \%$. All patients had pancolitis, and the surgical indications were refractory symptoms in five patients and cancer in two patients. Refractory patients tended to develop PCE relatively earlier than cancer patients. The extent of disease included various types, such as pan-enteritis with diffuse type, panenteritis and mild inflammation in the middle ileum, only ileitis, and concomitant diversion ileitis/pouchitis. The symptoms included abdominal pain, HOP syndrome, hemorrhage, and sometimes acute perforation or massive bleeding, which can be fatal. We previously reported four cases of UCrelated enteritis with only intestinal bleeding[25]. This study included all symptoms. GDUC developed in 6/7 cases. Regarding therapeutic outcomes, all patients improved with TNF $\alpha$ antagonists even if TNF $\alpha$ antagonists had failed as a treatment for colitis, which was reported in our study.

We searched the PubMed and Embase databases using the terms "ulcerative colitis" and "post-colectomy enteritis" or "pan-enteritis" or "diffuse enteritis" or "pre-stomal enteritis" or "small bowel lesion" in English before June 1, 2020. Thirty-seven cases were previously reported[10-14,26-32]. This rare disease with distinct endoscopic inflammation of the stomach and small bowel resembles inflammation in the colon with UC. Almost all patients with pancolitis underwent colectomy for a refractory disease, and many patients developed GDUC at the same time. These features were similar to the findings of our study. However, there are various names for enteritis, and the definition of time of enteritis onset is vague. Some cases of enteritis developed after stoma closure and before initial surgery. These cases of enteritis could overlap with prepouch ileitis and backwash ileitis. Moreover, the extent of disease and morphology of the ulcers varied in this study. Therefore, we limited the duration from post-colectomy to stoma closure, and we grouped these conditions as "PCE" in this study.

Hisabe et al. reported that the incidence of small bowel lesions was relatively high, and they found lesions postproctocolectomy in 11 of the 30 patients (36.6\%) with active UC by using wireless capsule endoscopy; some lesions were related to GDUC owing to ulcers arising from the duodenum[33]. Additionally, Hori et al. reported that a high proportion of GDUC associated with UC may not be restricted to the colon and that this condition might be concealed by the administration of corticosteroids[16]. Therefore, small bowel lesions might also be concealed for the same reason. After surgery, there were no therapeutic modifications, so small-intestinal inflammation might become apparent, and in patients with cancer, the disease severity was mild. Thus, the development of PCE might be delayed in this study.

Hoentjen et al. reported that the diagnosis of PCE should be based on underlying UC (pancolitis and status postcolectomy), symptoms (vomiting, diarrhea, and dehydration), endoscopy findings (UC-like pan-enteritis), the absence of infections or Crohn's-like complications (lack of positive cultures, fistulas, and abscesses), pathological findings (UC-like mucosal inflammation), and response to treatment (rapid improvement with IV corticosteroids within 24 h)[11]. In this study, we referred to the above criteria and diagnosed PCE based on exclusion criteria. This was difficult with the exclusion diagnosis, if we limit the discussion to $\mathrm{CMV}$ enteritis with UC. The appropriate diagnostic test for CMV, the optimal time to start antiviral therapy, and to the method of altering immunosuppressant medications remain unclear. In this study, one patient was initially diagnosed with CMV enteritis but was then diagnosed with PCE. CMV enteritis could be concomitant with refractory UC-related enteritis, such as colitis. Therefore, as in the case of colitis, it is necessary to further explore which patients require $\mathrm{GCV}$ treatment.

Intravenous corticosteroids and azathioprine were the 
most frequently reported treatments that were immediately administered[10,11]. TAC, IFX, and ADA were reported in only case reports[13,29,30]. A chimeric monoclonal antibody directed against TNF $\alpha$ is commonly effective for patients with UC[34,35]. It is still unclear whether TNF $\alpha$ antagonists could be effective for patients with UC and smallintestinal inflammation after colectomy. However, all patients with PCE were effectively treated in this study. The cause of refractory corticosteroids in three cases is unknown (cases 1,2, and 3). The effectiveness of TNF $\alpha$ antagonists in this study suggests that the first-choice treatment for PCE is TNF $\alpha$ antagonists. Moreover, TNF $\alpha$ antagonists were effective even if the patients had been unresponsive to TNF $\alpha$ antagonist treatment for colitis before surgery. Another consideration is the time and challenges associated with diagnosing CMV enteritis. In addition, $\mathrm{TNF} \alpha$ antagonists were previously reported to not be associated with an increased risk of CMV reactivation and did not adversely affect the outcomes of patients with CMV reactivation[36-38]. These considerations indicate that $\mathrm{TNF} \alpha$ antagonists are a feasible option. However, TNF $\alpha$ antagonists may not be suitable for postoperative patients with cancer. Cases 2 and 3 were steroid resistant and continued bleeding; thus, biologics were administered under sufficient informed consent about the risk of neoplasia. Although there seems to be no causal relationship between cancer recurrence and the use of biologics (case 3), TNFo antagonists should be avoided as first-line therapy in patients with cancer.

Some limitations were present in this study. First, this was a retrospective study with a small number of patients with PCE from a single center. Second, the long-term outcomes are unclear, and only two patients were followed up for over 5 years. However, these patients did not have pouch failure or progress to $\mathrm{CD}$. Third, serum evaluations of celiac disease and autoimmune enteritis were not performed. The reason is that these diseases are very rare in Japan compared to in Europe, and serum evaluations are not covered by insurance in Japan. Fourth, the association between CMV enteritis and PCE is unclear. In this study, only the patients suspected of CMV were tested by DNA-PCR, which was not covered by insurance in Japan. In the future, it will be necessary to perform immunohistochemistry and examine the necessity of GCV treatment. Fifth, the relationships among backwash ileitis, pouchitis, prepouchitis, and PCE are still a matter of debate. It may be useful to analyze data from patients with these four conditions and discuss differences and similarities in a future study.

The incidence of PCE is very low. However, we should suspect PCE based on clinical symptoms such as HOP fistula, hemorrhage, abdominal pain, and small-intestinal perforation in the postoperative course. The mucosal endoscopic findings were friable mucosa and granular mucosa, and the extent of disease varied. In addition, TNF $\alpha$ antagonists have a certain effect and are feasible as one of the treatment options.

\section{Conflicts of Interest}

There are no conflicts of interest.

\section{Author Contributions}

YH: conception and design of the study; acquisition, analysis and interpretation of data; and drafting of the article. KH, KK, TM, RK, KK, NB, and MI: conception and design of the study and acquisition, analysis, and interpretation of data. MU and HI: acquisition of data; drafting of the article or its critical revising for important intellectual content; and provision of final approval. All authors have read and approved the manuscript.

Approval by Institutional Review Board (IRB)

This study was conducted in accordance with the guidelines of the Declaration of Helsinki and with the approval of the Institutional Review Board of Hyogo College of Medicine (no. 3529).

\section{References}

1. McCready FJ, Bargen JA. Involvement of the ileum in chronic ulcerative colitis. N Engl J Med. 1949 Jan; 240(4): 119-27.

2. Haskell H, Andrews CW, Reddy SI, et al. Pathologic features and clinical significance of "Backwash" ileitis in ulcerative colitis. Am J Surg Pathol. 2005 Nov; 29(11): 1472-81.

3. Arrossi AV, Kariv Y, Bronner MP, et al. Backwash ileitis does not affect pouch outcome in patients with ulcerative colitis with restorative proctocolectomy. Clin Gastroenterol Hepatol. 2011 Nov; 9(11): 981-8.

4. Heuschen UA, Hinz U, Allemeyer EH, et al. Backwash ileitis is strongly associated with colorectal carcinoma in ulcerative colitis. Gastroenterology. 2001 Mar; 120(4): 841-7.

5. Abdelrazeq AS, Wilson TR, Leitch DL, et al. Ileitis in ulcerative colitis: is it a backwash? Dis Colon Rectum. 2005 Nov; 48(11): 2038-46.

6. White E, Melmed GY, Vasiliauskas EA, et al. A prospective analysis of clinical variables, serologic factors, and outcome of ileal pouch-anal anastomosis in patients with backwash ileitis. Dis Colon Rectum. 2010 Jul; 53(7): 987-94.

7. Hahnloser D, Pemberton JH, Wolff BG, et al. Results at up to 20 years after ileal pouch-anal anastomosis for chronic ulcerative colitis. Br J Surg. 2007 Mar; 94(3): 333-40.

8. Rottoli M, Vallicelli C, Bigonzi E, et al. Prepouch ileitis after ileal pouch-anal anastomosis: patterns of presentation and risk factors for failure of treatment. J Crohns Colitis. 2018 Feb; 12(3): 273-9.

9. Segal JP, McLaughlin SD, Faiz OD, et al. Incidence and long-term implications of prepouch ileitis: an observational study. Dis Colon Rectum. 2018 Apr; 61(4): 472-5.

10. Corporaal S, Karrenbeld A, van der Linde K, et al. Diffuse enteritis after colectomy for ulcerative colitis: two case reports and review of the literature. Eur J Gastroenterol Hepatol 2009 Jun; 21 (6): 710-5.

11. Hoentjen F, Hanauer SB, Hart J, et al. Long-term treatment of pa- 
tients with a history of ulcerative colitis who develop gastritis and pan-enteritis after colectomy. J Clin Gastroenterol. 2013 Jan; 47 (1): 52-7.

12. Haboubi N. Small bowel inflammation in ulcerative colitis. Colorectal Dis. 2006 Jun; 8(5): 373-4.

13. Rush B, Berger L, Rosenfeld G, et al. Tacrolimus therapy for ulcerative colitis-associated post-colectomy enteritis. ACG Case Rep J. 2014 Oct; 2(1): 33-5.

14. Feuerstein JD, Shah $S$, Najarian $R$, et al. A fatal case of diffuse enteritis after colectomy for ulcerative colitis: a case report and review of the literature. Am J Gastroenterol. 2014 Jul; 109(7): 10869.

15. Truelove SC, Witts LJ. Cortisone in ulcerative colitis; final report on a therapeutic trial. Br Med J. 1955 Oct; 2(4947): 1041-8.

16. Hori K, Ikeuchi H, Nakano H, et al. Gastroduodenitis associated with ulcerative colitis. J Gastroenterol. 2008; 43(3): 193-201.

17. Yokota K, Saito Y, Einami K, et al. A bamboo joint-like appearance of the gastric body and cardia: possible association with Crohn's disease. Gastrointest Endosc. 1997 Sep; 46(3): 268-72.

18. Ueno F, Matsui $T$, Matsumoto $T$, et al. Evidence-based clinical practice guidelines for Crohn's disease, integrated with formal consensus of experts in Japan. J Gastroenterol. 2012 Jan; 48(1): 31-72.

19. Silverberg MS, Satsangi J, Ahmad T, et al. Toward an integrated clinical, molecular and serological classification of inflammatory bowel disease. Report of a Working Party of the 2005 Montreal World Congress of Gastroenterology. Can J Gastroenterol. 2005 Sep; 19(Suppl A): 5A-36A.

20. Criteria for diagnosis of Behçet's disease. International Study Group for Behçet's disease. Lancet. 1990 May; 335(8697): 107880.

21. Talley NJ, Shorter RG, Phillips SF, et al. Eosinophilic gastroenteritis: a clinicopathological study of patients with disease of the mucosa, muscle layer, and subserosal tissues. Gut. 1990 Jan; 31 (1): 54-8.

22. Ozen S, Pistorio A, Iusan SM, et al. EULAR/PRINTO/PRES criteria for Henoch-Schönlein purpura, childhood polyarteritis nodosa, childhood Wegener granulomatosis and childhood Takayasu arteritis: Ankara 2008. Part II: Final classification criteria. Ann Rheum Dis. 2010 May; 69(5): 798-806.

23. Dickson BC, Streutker CJ, Chetty R. Coeliac disease: an update for pathologists. J Clin Pathol. 2006 Oct; 59(10): 1008-16.

24. Akram S, Murray JA, Pardi DS, et al. Adult autoimmune enteropathy: Mayo Clinic Rochester experience. Clin Gastroenterol Hepatol. 2007 Nov; 5(11): 1282-90.

25. Uchino M, Matsuoka $H$, Bando $T$, et al. Clinical features and treatment of ulcerative colitis-related severe gastroduodenitis and enteritis with massive bleeding after colectomy. Int $\mathrm{J}$ Colorectal Dis, 2014 Feb; 29(2): 239-45.

26. Gooding IR, Springal R, Talbot IC, et al. Idiopathic smallintestinal inflammation after colectomy for ulcerative colitis. Clin
Gastroenterol Hepatol. 2008 Jun; 6(6): 707-9.

27. Nakajima M, Nakashima $H$, Kiyohara $K$, et al. Case with diffuse deodenitis and enteritis following total colectomy for ulcerative colitis. Nihon Shokakibyo Gakkai Zasshi. 2008 Mar; 105(3): 38290.

28. Yang Y, Liu Y, Zheng W, et al. A literature review and case report of severe and refractory post-colectomy enteritis. BMC Gastroenterol. 2019 Apr; 19(1): 61.

29. Okabayashi S, Kobayashi T, Sujino T, et al. Steroid-refractory extensive enteritis complicated by ulcerative colitis successfully treated with adalimumab. Intest Res. 2017 Oct; 15(4): 535-9.

30. Akitake R, Nakase H, Tamaoki M, et al. Modulation of Th1/Th2 balance by infliximab rescues postoperative occurrence of smallintestinal inflammation associated with ulcerative coltis. Dig Dis Sci. 2010 Jun; 55(6): 1781-4.

31. Annese V, Caruso N, Bisceglia M, et al. Fatal ulcerative colitis panenteritis following colectomy in a patient with ulcerative colitis. Dig Dis Sci. 1999 Jun; 44(6): 1189-95.

32. Ninomiya K, Hisabe T, Okado $\mathrm{Y}$, et al. Comparison of small bowel lesions using capsule endoscopy in ulcerative colitis and Crohn's disease: a single-center retrospective analysis. Digestion. 2018; 98(2): 119-26.

33. Hisabe T, Ninomiya K, Matsui $T$, et al. Small bowel lesions detected with wireless capsule endoscopy in patients with active ulcerative colitis and with post-proctocolectomy. Dig Endosc. 2011 Oct; 23(4): 302-9.

34. Kohn A, Daperno M, Armuzzi A, et al. Infliximab in severe ulcerative colitis: short-term results of different infusion regimens and long-term follow-up. Aliment Pharmacol Ther. 2007 Sep; 26 (5): 747-56.

35. Rutgeerts $\mathrm{P}$, Sandborn WJ, Feagan BG, et al. Infliximab for induction and maintenance therapy for ulcerative colitis. N Engl J Med. 2005 Dec; 353(23): 2462-76.

36. Shukla T, Singh S, Tandon $P$, et al. Corticosteroids and thiopurines, but not tumor necrosis factor antagonists, are associated with cytomegalovirus reactivation in inflammatory bowel disease: a systematic review and meta-analysis. J Clin Gastroenterol. 2017 May/Jun; 51(5): 394-401.

37. Pillet $S$, Jarlot $C$, Courault $M$, et al. Infliximab does not worsen outcomes during flare-ups associated with cytomegalovirus infection in patients with ulcerative colitis. Inflam Bowel Dis. $2015 \mathrm{Jul}$; 21(7): 1580-6.

38. Tun GSZ, Raza M, Hale MF, et al. Polymerase chain reaction for detection of mucosal cytomegalovirus infection in patients with acute ulcerative colitis. Ann Gastroenterol. 2019 Jan-Feb; 32(1): 81-7.

Journal of the Anus, Rectum and Colon is an Open Access journal distributed under the Creative Commons Attribution-NonCommercial-NoDerivatives 4.0 International License. To view the details of this license, please visit (https://creativ ecommons.org/licenses/by-nc-nd/4.0/). 